\title{
Antidiuretic Effects of Dibutyryl-Cyclic AMP Microinjected into the Hypothalamic Supraoptic Nucleus in Water-Loaded and Ethanol-Anesthetized Rats
}

\author{
Mayumi MORI, Hiromi TSUSHIMA and Tomohiro MATSUDA \\ Department of Pharmacology, Nagova City University Medical School. \\ Kawasumi, Mizuho-ku, Nagoya 467, Japan \\ Accepted July 24, 1986
}

\begin{abstract}
Effects of dibutyryl-cyclic AMP (db-cAMP) and cyclic AMP (cAMP) microinjected into the hypothalamic supraoptic nucleus (SON) which contains the neurons synthesizing and releasing antidiuretic hormone upon the outflow and the osmotic pressure of urine and the other visceral functions were investigated in water-loaded rats anesthetized with ethanol. When microinjected into the SON the dibutyryl analog of CAMP induced dose-dependent antidiuretic effects without significant effects on any other visceral functions. Dibutyryl-cAMP was much more effective than cAMP: The ED50 value for db-CAMP was approx. $200 \mathrm{nmol}$ versus more than $500 \mathrm{nmol}$ for CAMP. The time course of the antidiuretic effects was relatively slow with minimal urine outflow appearing only after more than $1 / 2$ hour post-injection. The effects induced by $\mathrm{db}$-cAMP demonstrated tachyphylaxis and were partially inhibited by pretreatment with atropine or theophylline, which suggests that the antidiuretic effects were mediated through muscarinic and adenosine receptors present in the nucleus.
\end{abstract}

The supraoptic nucleus (SON) in the hypothalamus as well as the paraventricular nucleus (PVN) is known to contain magnocellular neurons which synthesize and release antidiuretic hormone $(\mathrm{ADH})$, vasopressin. The hormone is synthesized in the neuronal cell bodies in the SON and transported to the neurohypophysis through axonal tracts. When the neurons in the SON are stimulated by neurotransmitters, the hormone is released from the neurohypophysis into the circulation and enhances water reabsorption from the distal tubules and collecting ducts of the kidney, resulting in antidiuresis (1-6).

The presence of an acetylcholine (ACh) system in the nuclei $(7,8)$ and the finding that iontophoretic application of $\mathrm{ACh}$ excites the neurons of the nuclei (9-13) have suggested a role for cholinergic innervation within the nuclei. Microinjection of muscarinic agonists such as oxotremorine and ACh into the nucleus causes potent antidiuretic effects which are blocked completely by pre-microinjection of a muscarinic antagonist, atropine, thus indicating that it was stimulation of muscarinic receptors in the nuclei which induced antidiuretic effects (14)

Histofluorescent visualization of catecholamine-containing varicosities and immunohistochemical visualization of catecholamine-synthesizing enzyme-containing nerve terminals synapsing on the magnocellular neurons in the nuclei strongly suggest adrenergic regulation of $\mathrm{ADH}$ release (15-18). The microinjection of the beta-adrenoceptor agonist, isoproterenol into the nuclei induces a strong antidiuretic effect, which is stereospecific and blocked completely by betaadrenoceptor antagonist (19, 20).

We demonstrated earlier that when adenosine-3',5'-cyclic monophosphate (cAMP). known as a second messenger for betaadrenoceptor stimulation, or its analog, dibutyryl-cAMP (db-cAMP), are microinjected into the PVN, they also induced 
antidiuretic effects which showed tachyphylaxis and were completely blocked by pre-microinjection of a muscarinic antagonist (21). In the present study, we report effects of the cyclic nucleotides microinjected into the SON, another nucleus which is also stimulated by beta-adrenoceptor agonists (19. 20).

\section{Materials and Methods}

Animals and drugs: Male Wistar rats, weighing $280-320 \mathrm{~g}$. were used. Adenosine3',5'-cyclic monophosphate (CAMP) sodium salt and $N^{6},-O^{2}$-dibutyryl-adenosine- $3^{\prime}, 5^{\circ}$ cyclic monophosphate (db-cAMP) sodium salt (Sigma Chemical Co. St. Louis, MO). atropine sulfate (Iwaki Co., Tokyo), phenoxybenzamine hydrochloride (Nakarai Chemicals. Kyoto), theophylline (Wako Pure Chemical Industries, Ltd., Osaka), and 3-isobutyl-1methylxanthine (IBMX, Sigma Chemical Co. St. Louis, MO) were purchased. Timolol malate was a generous gift from Nippon MerckBanyu Co., Tokyo. The other chemicals used were of the highest analytical grade available.

Measurement of urine outflow and urine osmotic pressure: Urine outflow was measured by the method of Dicker, with some modifications $(14,22)$. The rats were starved overnight for approx. $17 \mathrm{hr}$, but had free access to water. The animals were loaded orally through a catheter with a volume of water equivalent to $5 \%$ of the body weight followed by the same volume of $12 \%$ ethanol. Cannulae were inserted into the trachea, bladder and external jugular vein. The rat was then immobilized in a stereotaxic instrument for rats (Takahashi Co., Tokyo). Drops of urine flowing from the urinary cannula were counted using a photoelectric drop counter (DCT 102, Unique Medical Inc. Tokyo) and recorded as single pulses. Ethanol $(3 \%$ in Locke solution) was infused at a constant rate of $0.10 \mathrm{ml} / \mathrm{min}$ through the cannula in the jugular vein in order to maintain a constant level of anesthesia and a constant rate of urine outflow. Osmotic pressure of the urine was measured by the freezing point depression method (The Fiske Osmometer. Model G-62. Fiske Associates, Inc., Uxbridge, MA)

Microinjection of drugs: A stainless steel cannula (outer diameter: $200 \mu \mathrm{m}$ ) was unilaterally inserted stereotaxically into the SON according to the atlas of König and Klippel (23). Dibutyryl-cAMP and CAMP were dissolved in saline ( $\mathrm{pH}$ approx. 7). IBMX was dissolved in 3\% ethanol in saline ( $\mathrm{pH}$ approx. 7), and other compounds were dissolved in saline ( $\mathrm{pH}$ approx. 7) or in an artificial cerebrospinal fluid (CSF: $128 \mathrm{mM}$ $\mathrm{NaCl}, 3.0 \mathrm{mM} \mathrm{KCl}, 1.2 \mathrm{mM} \mathrm{CaCl}_{2}, 0.8 \mathrm{mM}$ $\mathrm{MgCl}_{2}, 0.65 \mathrm{mM} \mathrm{NaH} \mathrm{PO}_{4}$ and $4.8 \mathrm{mM}$ $\mathrm{NaHCO}_{3}, \mathrm{pH} 7.4$ ). Microinjection of $1 \mu l$ of each respective drug was performed when the urine outflow reached a constant rate of $0.04-0.23 \mathrm{ml} / \mathrm{min}$ which was within one hour after the animal was fixed in the stereotaxic instrument. Then the artificial CSF $(2 \mu)$ was infused at a rate of approx. $0.3 \mu l / \mathrm{min}$. Effects of drugs on urine outflow were measured at 10 min-intervals and expressed as a percent of the initial control outflow.

In the experiment to test the effect of pretreatment with atropine and timolol, microinjection of $\mathrm{db}$-cAMP was carried out at $30-$ 60 min after microinjection of atropine, when the urine outflow had returned to the initial level, and at 20-30 min after microinjection of timolol, respectively. In the experiments to see the effects of pretreatment with phenoxybenzamine or phosphodiesterase inhibitors, the time interval between microinjections was $20 \mathrm{~min}$. The effect of pre-injection of a drug was estimated as the change in antidiuretic effect caused by the injection of $\mathrm{db}$-cAMP with and without the pretreatment. This was done in separate rats because of the tachyphylaxis in antidiuresis induced by the dibutyryl analog.

Identification of the sites of inserted cannula: The position of the tip of the cannula within the SON was confirmed by the following methods: 1) functionally, by the appearance of an antidiuretic effect by the microinjection of a depolarizing dose $(800$ nmol) of $\mathrm{KCl}$ through the cannula and 2) histochemically, by localization of the site of the tip of the cannula in a group of magnocellular cells in the SON positively stained by the method of Gomori (24).

Measurement of blood pressure, heart rate, respiration rate and rectal temperature: Mean blood pressure and heart rate were 
measured through a cannula inserted into the carotid artery using, respectively, a pressure transducer (MPU-0.5-290-O-lll, Nihon Kohden Kogyo, Co., Tokyo) and an electrocardiograph (FD-14, Fukuda. Tokyo). Respiration rate was measured via a thermister probe (SR-115S. Nihon Kohden Kogyo, Co.) inserted into a tracheal catheter. These three indices were recorded simultaneously on a recticorder (RJG-3004-2. Nihon Kohden Kogyo. Co.). Rectal temperature was monitored by a thermister probe (MGA III-219. Nihon Kohden Kogyo, Co.) inserted into the rectum.

Statistical analysis: Significance of differences between mean values was determined by Student's $t$-test. Differences were considered significant at $P<0.05$. The ED50 values and $95 \%$ confidence limit of the ED50 values were computed from dose-effect curves drawn using the least squares method.

\section{Results}

Effects of microinjection of db-cAMP and cAMP on urine outflow: Figure 1 a shows the effects of various doses of $\mathrm{db}$-cAMP on urine outflow as a function of length of time after their microinjection into the SON. Dibutyryl-
CAMP caused a dose-dependent antidiuretic effect. Urine outflow decreased within 20-30 min, with a minimal outflow at $30-40 \mathrm{~min}$ after microinjection of $\mathrm{db}$-cAMP. It returned to the initial control levels at approx. $70 \mathrm{~min}$ after microinjection of either 30 or $100 \mathrm{nmol}$ $\mathrm{db}$-CAMP. After injection of higher dose $(500$ nmol), urine outflow returned only to $50 \%$ of the initial control levels by $80 \mathrm{~min}$ after microinjection. When vehicle alone was microinjected there was no change in urine outflow. As shown in Fig. 1b, the antidiuretic effect of microinjection of CAMP was much less with larger deviations than that of $\mathrm{db}$ CAMP, and recovery was earlier (within 50 $\mathrm{min}$ ) after microinjection of $500 \mathrm{nmol}$ cAMP.

Dose-effect curve for db-cAMP and the effect of cAMP: Figure 2 shows the doseeffect curve for the antidiuresis induced by db-CAMP compared with the effect of 500 nmol CAMP injected into the SON. The antidiuretic effect on the ordinate shows the minimal urine outflow measured at 10 minintervals, presented as percentage of the initial urine outflow. The approx. median effective doses (ED50) were estimated to be 200 (121-331) nmol for db-cAMP and more than $500 \mathrm{nmol}$ for cAMP.

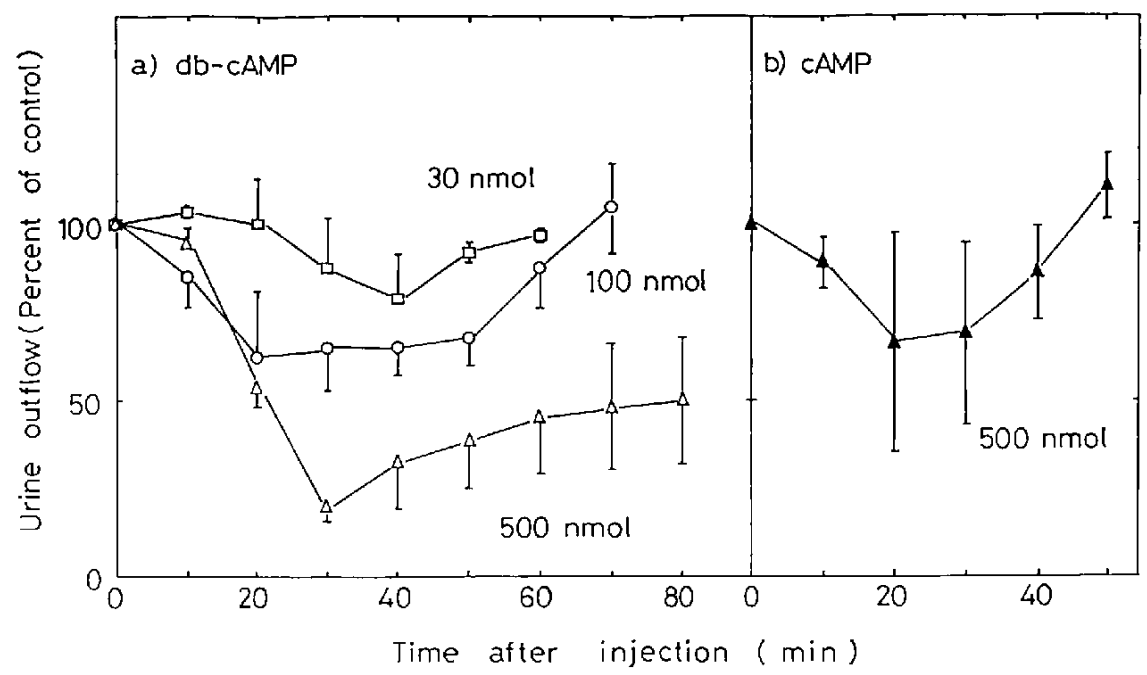

Fig. 1. Time-courses for antidiuresis by microinjection of cyclic nucleotides into the SON. a): db-cAMP: b) : CAMP. Abscissa indicates time in min after microiniection of $1 \mu \mid$ of drug solution and ordinate shows urine outflow presented as percent of the initial control urine outflow $(a, 0.094 \pm 0.010 ; b, 0.083 \pm 0.003$ $\mathrm{ml} / \mathrm{min}$ ). Symbols which represent the urine outflow during the immediately preceding $10 \mathrm{~min}$ period are the means \pm S.E. from $3-4$ experiments. 
Inhibition of db-cAMP-induced antidiuresis by pretreatment with atropine and theophylline: As shown in Table 1, a preinjection of $300 \mathrm{nmol}$ atropine or $50 \mathrm{nmol}$

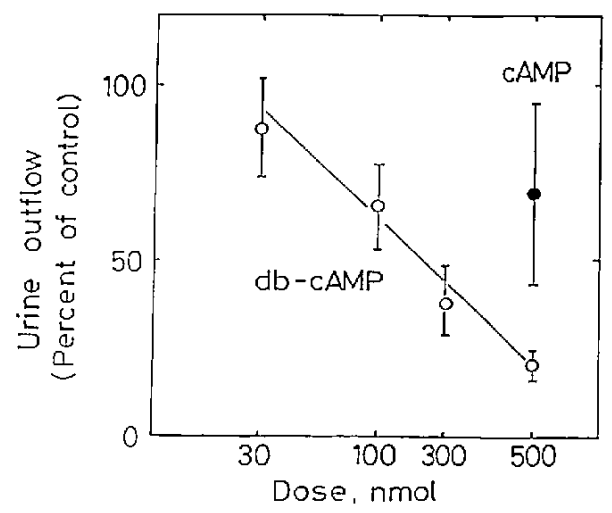

Fig. 2. Dose-effect curve for the antidiuretic effects of $\mathrm{db}-\mathrm{CAMP}$ and CAMP microinjected into the SON. Abscissa indicates the dose of the cyclic nucleotides and ordinate shows the minimal urine outflow during the immediately preceding $10 \mathrm{~min}$ measured $30-50$ min after microinjection and presented as percentage of the initial urine outflow (for db-CAMP: $0.094 \pm 0.010$ : for CAMP: $0.083 \pm 0.003 \mathrm{ml} / \mathrm{min}$ ). Symbols represent the means \pm S.E. from 4-6 experiments. theophylline partially inhibited the antidiuretic effect induced by microinjection of $300 \mathrm{nmol} \mathrm{db}$-cAMP into the SON. Preinjection of either phenoxybenzamine $(80$ $\mathrm{nmol}$ ) or timolol (100 nmol) did not interfere with the effect of $\mathrm{db}$-cAMP. Pretreatment with $10 \mathrm{nmol}$ isobutyl methylxanthine (IBMX) tended to inhibit the effect of $\mathrm{db}$ CAMP but not significantly. Antidiuretic effects induced by $\mathrm{ACh}$ (14), norepinephrine (19) and isoproterenol (19) microinjected into the SON have been reported to be completely blocked by these doses of atropine, phenoxybenzamine and timolol, respectively. The doses of theophylline and IBMX described above have also described as being able to potentiate the antidiuretic effects of db-cAMP and CAMP respectively when they were microinjected into the PVN (21).

Tachyphylaxis in the antidiuretic effect by microinjection of db-cAMP: Figure 3 demonstrates the antidiuretic effects induced by the first and the second microinjections of 300 $\mathrm{nmol} \mathrm{db}$-cAMP into the SON as a function of time after each microinjection. The effect of the second microinjection was significantly less than that of the first, while antidiuretic

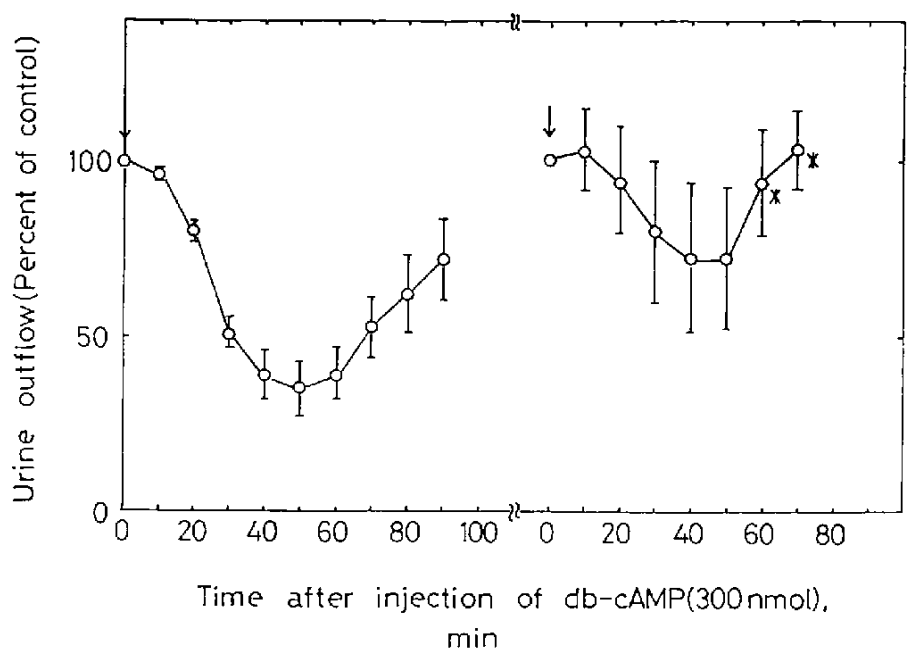

Fig. 3. Antidiuretic effects induced by repeated microinjection of db-CAMP into the SON. DibutyrylcAMP (300 nmol) was injected twice, at the times indicated by the arrows. The time interval between the two arrows was approx. two hours. Abscissa and ordinate are as in Fig. 1. Initial urine outflows were $0.096 \pm 0.014$ and $0.087 \pm 0.010 \mathrm{ml} / \mathrm{min}$ during the preceding $10 \mathrm{~min}$ at the time of the first and the second microinjection, respectively. Symbols represent the means \pm S.E. from 7 experiments. Significance compared with the values for the first microinjection of $\mathrm{db}$-CAMP at the same time points: ${ }^{*} \mathrm{P}<0.05$. 


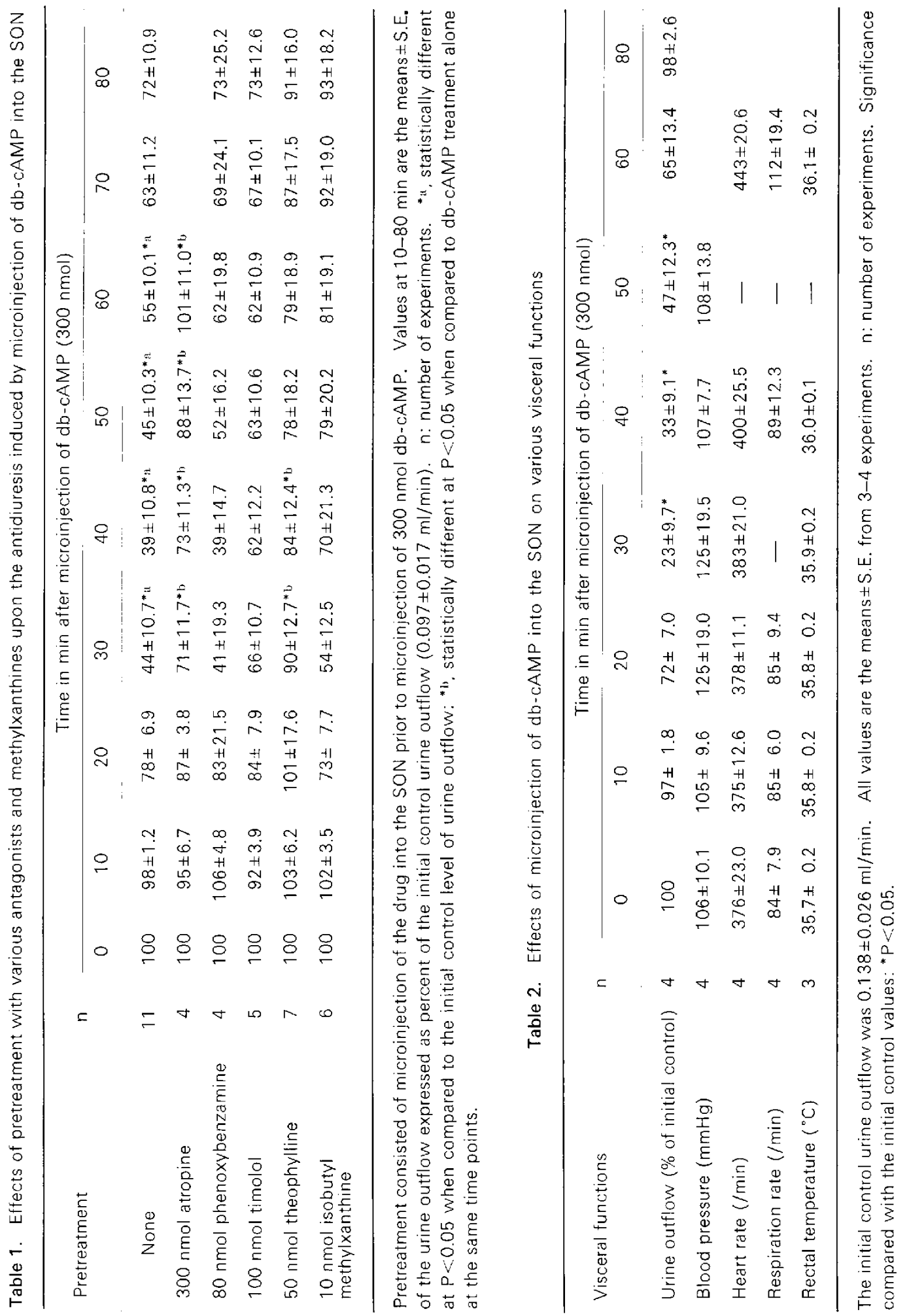


effects caused by a second microinjection of $\mathrm{KCl}$, cholinergic agonists, and adrenoceptor agonists except epinephrine were approx. equal to the effects of the first microinjection $(14,19)$.

Effect of microinjection of db-cAMP on urine osmotic pressure: Figure 4 shows the effects of microinjection of $\mathrm{db}$-CAMP into the SON on urine osmotic pressure at two points: at the time when the urine outflow had decreased to minimal levels and at the time it recovered to the initial control levels.

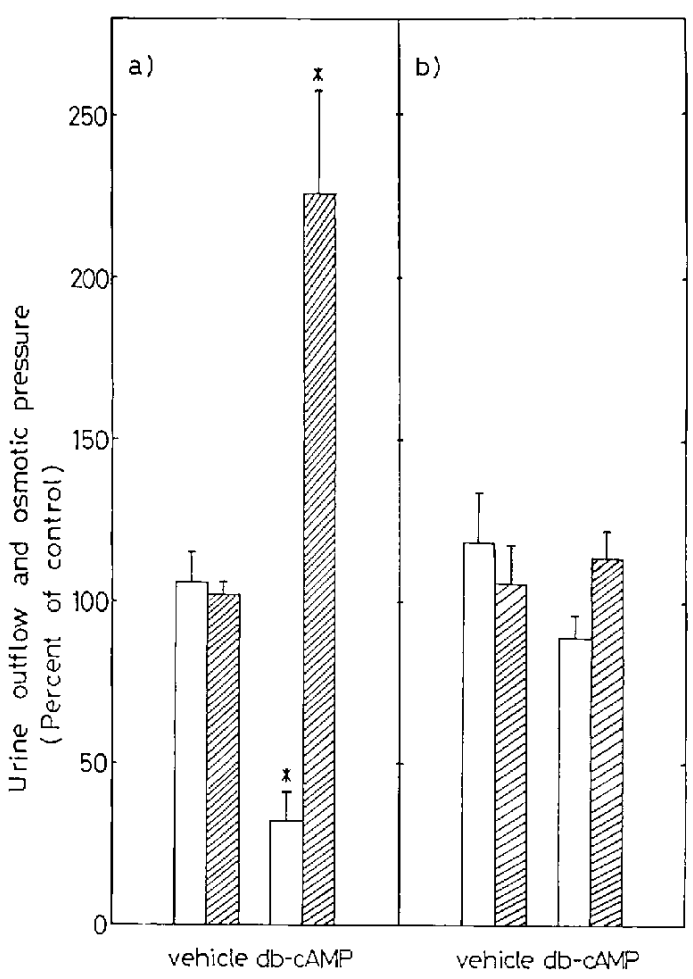

Fig. 4. Changes in urine osmotic pressure compared with urine outflow after microinjection of $\mathrm{db}$ CAMP into the SON. Open column: urine outflow: hatched column: urine osmotic pressure, expressed as percent of the initial control values (initial urine outflow: $0.15 \pm 0.022 \mathrm{ml} / \mathrm{min}$, initial urine osmotic pressure: $162 \pm 8.7 \mathrm{mOsm})$, a): when the urine outflow was approx. minimal, i.e. 30 min after microinjection of $300 \mathrm{nmol} \mathrm{db}-\mathrm{cAMP}, \mathrm{b})$ : when the outflow had recovered to the initial level at 60-90 mir after the microinjection. Each column represents the means $\pm S . E$. from 3-4 experiments. Significance compared with the value for microinjection of vehicle: ${ }^{*} P<0.05$.
At 30 min after microinjection when the urine outflow decreased to approx. $30 \%$ of the initial control, the osmotic pressure increased to approx. $230 \%$ of control. Both urine outflow and osmotic pressure had recovered by $60-$ 90 min after microinjection.

Effect of microinjection of db-cAMP into the SON on visceral functions: Some visceral indices which might be expected to be responsive to the microinjection of $\mathrm{db}-\mathrm{cAMP}$ into the SON and which might affect the urine outflow were also monitored during the experiments. Table 2 is a summary of the results. At $30 \mathrm{~min}$ and at $40 \mathrm{~min}$ after injection of $300 \mathrm{nmol}$ db-cAMP, when a marked decrease in the urine outflow had occurred, there were no significant changes in mean blood pressure, heart rate, respiration rate and rectal temperature.

\section{Discussion}

To our knowledge this is the first study that demonstrates the antidiuretic effect of $\mathrm{db}$ CAMP injected directly into the SON in which are found the magnocellular neurons synthesizing and releasing antidiuretic hormone (ADH). Both CAMP and its dibutyryl analog induced dose-dependent antidiuresis. Cyclic $A M P$, for which the ED50 value was more than $500 \mathrm{nmol}$ was more than 2.5 times weaker than db-CAMP, with an ED50 of 200 nmol. Since the ED50 value for $\mathrm{db}$-cAMP microinjected into the PVN is approx. $40 \mathrm{nmol}$ (21). the sensitivity of the SON to db-cAMP seems to be approx. One fifth less than that of the PVN. The time course of the effect was relatively slow, with a maximal effect (i.e. minimal urine outflow) at $30-40 \mathrm{~min}$. The effect lasted as long as 70 min after microinjection, as has been reported in the case of antidiuretic effects induced by microinjection of various agonists into the SON $(14,19)$. Along with the decrease in urine outflow there was a concomitant increase in urine osmotic pressure, indicating that the decrease in urine outflow was due to mainly the enhancement of water reabsorption by the kidney.

The ED50 values of $\mathrm{KCl}$ and $\mathrm{db}-\mathrm{CAMP}$ for antidiuretic effects in the SON were approx. 850 (14) and $200 \mathrm{nmol}$, respectively. Therefore, the median effective concentration for 
db-cAMP can be roughly estimated to be approx. $7 \mathrm{mM}$, which is a higher concentration than the effective concentration usually used $(25,26)$, provided the central neurons are depolarized by $\mathrm{KCl}$ at approx. $30 \mathrm{mM}$ concentration. As rats were loaded with water and ethanol in order to keep the urine outflow constant and at a measurable flow rate in the present experiments, the true effective concentration for $\mathrm{db}$-cAMP in unanesthetized rats without water- and ethanol-loading could be lower than the value estimated above. The median effective concentration mentioned above for $\mathrm{db}$-CAMP microinjected into the SON was a little higher than that for $\mathrm{db}$-CAMP microinjected into the PVN, which was approx. $4 \mathrm{mM}$ (21), under the same condition of water-loading and ethanol-anesthetizing.

Pretreatment with a muscarinic antagonist, atropine, which blocked completely the antidiuretic effect of $\mathrm{db}$-CAMP when microinjected into the PVN (21), only partially inhibited the effect of db-CAMP when it was microinjected into the SON: this suggests that only part of the effect of $d b$-cAMP on the SON is mediated through muscarinic receptors. As discussed in our previous paper (21), a possible explanation for this observation is that $\mathrm{db}$-cAMP releases a muscarinic substance, probably $\mathrm{ACh}$, from presynaptic cholinergic nerve terminals in the nucleus ( 7 , 8 ) as has been reported in the brain $(25,27$. 28), neuromuscular junction (29), and small intestine $(30,31)$.

The stronger potency of $d b-C A M P$, which is more permeable through the plasma membrane (32) suggests that the effect may be related to an increased intracellular level of cAMP. However, it remains to be elucidated why theophylline, an inhibitor of phosphodiesterase, was unable to potentiate, and in fact partially inhibited the effects of $\mathrm{db}$ CAMP. One explanation for this may be that $\mathrm{db}-\mathrm{CAMP}$ released a purinergic agonist such as ATP, as well as ACh, and the agonist induced an antidiuretic effect through adenosine receptors in the SON, since we have shown that microinjection of ATP into the SON induced antidiuresis which could be inhibited by pretreatment with theophylline (M. Mori, H. Tsushima and T. Matsuda, in preparation) which is an antagonist of the adenosine receptor (26).

Tachyphylaxis in the db-CAMP-induced antidiuresis reported here in the SON, as well as in the PVN (21), could be due to the depletion of small pools of the neurotransmitters in the presynaptic areas.

During antidiuresis induced by microinjection of db-cAMP (300 nmol), no significant changes which might affect the urine outflow were observed in various visceral functions such as mean blood pressure, heart rate, respiration rate and rectal temperature. Therefore, the antidiuretic effect of $d b-c A M P$ is not likely to be due to the changes in these visceral functions.

In summary, the present study demonstrated for the first time an antidiuretic effect of db-CAMP injected directly into the SON, which contains the neurons which synthesize and release $A D H$. The effect of $d b-c A M P$ was inhibited partially by pretreatment with atropine and theophylline, suggesting that a significant part of the effect of $\mathrm{db}$-CAMP may be mediated through muscarinic and adenosine receptors. Further investigation will be necessary to uncover the evidence to support this suggestion.

Acknowledgements: The authors thank Dr. Yasuhiro Hasegawa. Department of Physiology in our Medical School, for computing the ED50 values. This work was supported by research grants from the Japanese Ministry of Education. Science and Culture (No. 60126001) and from the Research Foundation for Oriental Medicine, Nagoya, Japan.

\section{References}

1 Reichlin, S.: Neuroendocrinology. In Textbook of Endocrinology, Edited by Williams, R.H.. p. 589645. W.B. Saunders Co., Philadelphia (1981)

2 Schrier, R.W. and Leaf, A.: Effects of hormones on water, sodium, chloride, and potassium metabolism. In Textbook of Endocrinology. Edited by Williams, R.H., p. 1032-1046. W.B. Saunders Co.. Philadelphia (1981)

3 Zimmerman, E.A.: Oxytocin, vasopressin, and neurophysins. In Brain Peptides, Edited by Krieger, D.T., Brownstein, M. J. and Martin, J.B., p. 597-611. John Wiley \& Sons. New York (1983)

4 Reid, 1.A.: Salt and water regulation. In Brain Peptides. Edited by Krieger, D.T., Brownstein. M.J. and Martin, J.B., p. 333-347, John Wiley 
\& Sons, New York (1983)

5 Zimmerman, E.A., Hou-Yu, A., Nilaver, G. and Silverman, A.-J.: Anatomy of pituitary and extrapituitary vasopressin secretory systems. In The Neurohypophysis. Physiological and Clinical Aspects, Edited by Reichlin. S., p. 5-33. Plenum Medical Book Co. New York (1984)

6 Hays, R.M.: Agents affecting the renal conservation of water. In The Pharmacological Basis of Therapeutics, Seventh Edition, Edited by Goodman. A.G., Goodman. L.S., Rall, T.W., and Murad, F., p. 908-919, MacMillan Publishing Co., New York (1985)

7 Feldberg, W. and Vogt, M.: Acetylcholine synthesis in different regions of the central nervous system. J. Physiol. (Lond.) 107, 372-381 (1948)

8 Abrahams, V.C., Koelle, G.B. and Smart, P.: Histochemical demonstration of cholinesterases in the hypothalamus of the dog. J. Physiol. (Lond.) 139, 137-144 (1957)

9 Bloom, F.E., Oliver, A.P. and Salmoiraghi, G.C.: The responsiveness of individual hypothalamic neurons to microelectrophoretically administered endogenous amines. J. Neuropharmacol. 2, 181 193 (1963)

10 Barker, J.L., Crayton, J.W. and Nicoll, R.A.: Noradrenaline and acetylcholine responses of supraoptic neurosecretory cells. J. Physiol. (Lond.) 218, 19-32 (1971)

11 Dreifuss, J.J. and Kelly, J.S.: The activity of identified supraoptic neurons and their response to acetylcholine applied by iontophoresis. $J$. Physiol. (Lond.) 220, 105-118 (1972)

12 Barker, J.L., Crayton, J.W. and Nicoll, R.A.: Supraoptic neurosecretory cells: Adrenergic and cholinergic sensitivity. Science 171, 208-210 (1971)

13 Cross, B.A., Moss, R.L. and Urban, 1.: Effect of iontophoretic application of acetylcholine and noradrenaline to antidromically identified paraventricular neurones. J. Physiol. (Lond.) 214. 28P-30P (1971)

14 Mori, M., Tsushima, H. and Matsuda, T.: Antidiuretic effects of oxotremorine microinjected into the hypothalamic supraoptic and paraventricular nuclei in a water-loaded and ethanolanesthetized rat. Japan. J. Pharmacol. 35, 27-36 (1984)

15 McNeill, T.H. and Sladek, J.R., Jr.: Simultaneous monoamine histofluorescence and neuropeptide immunocytochemistry. Il. Correlative distribution of catecholamine varicosities and magnocellular neurosecretory neurons in rat supraoptic and paraventricular nuclei. \. Comp. Neurol. 193 , 1023-1033 (1980)
16 Swanson, L.W., Sawchenko, P.E., Bérod, A. Hartman, B.K., Helle, K.B. and Vanorden, D.E.: An immunohistochemical study of the organization of catecholaminergic cells and terminal fields in the paraventricular and supraoptic nuclei of the hypothalamus. J. Comp. Neurol. 196, 271-285 (1981)

17 Sawchenko, P.E. and Swanson, L.W.: Central noradrenergic pathways for the integration of hypothalamic neuroendocrine and autonomic responses. Science 214, 685-687 (1981)

18 Swanson, L.W. and Sawchenko, P.E.: Hypothalamic integration: Organization of the paraventricular and supraoptic nuclei. Annu. Rev. Neurosci. 6, 269-324(1983)

19 Tsushima, H., Mori, M. and Matsuda, T.: Antidiuretic effects of alpha-and beta-adrenoceptor agonists microinjected into the hypothalamic supraoptic nucleus in a water-loaded and ethanol-anesthetized rat. Japan. J. Pharmacol. 39, 365-374 (1985)

20 Tsushima, H., Mori, M. and Matsuda, T.: Antidiuretic effects of alpha- and beta-adrenoceptor agonists microinjected into the hypothalamic paraventricular nucleus in a water-loaded and ethanol-anesthetized rat. Japan. J. Pharmacol. 40, 319-328 (1986)

21 Mori, M., Tsushima, H. and Matsuda, T.: Antidiuretic effects of dibutyryl-cyclic AMP microinjected into the hypothalamic paraventricular nucleus in a water-loaded and ethanol-anesthetized rat. Japan. J. Pharmacol. 40, 311-318 (1986)

22 Dicker, S.E.: A method for the assay of very small amounts of antidiuretic activity with a note on the antidiuretic titre of rat's blood. J. Physiol. (Lond.) 122, 149-157 (1953)

23 König, J.F.R. and Klippel, R.A.: The Rat Brain, A Stereotaxic Atlas of the Forebrain and Lower Parts of the Brain Stem. Williams and Wilkins Co. Baltimore (1963)

24 Bargmann, W:: Über die neurosekretrische Verknüpfung von Hypothalamus und Neurohypophyse. Z. Zellforsch. 34, 610-634 (1949)

25 Katsuki, S., Matsuda, T., Hata, F. and Yoshida, $H .:$ Increase in ACh release from the rat brain cortex slices by $3^{\prime}, 5^{\circ}$-cyclic adenosine monophosphate. Japan. J. Pharmacol. 27, 173-175 (1977)

26 Rall, T.W.: Central nervous system stimulants. The methylxanthines. In The Pharmacological Basis of Therapeutics, Seventh Edition, Edited by Gilman, A.G., Goodman, L.S., Rall, T.W. and Murad. F., p. 589-603. MacMillan Publishing Co.. New York (1985) 
27 Matsuda, T., Yonehara, N., Noguchi, Y., Hata, F., Kuo, C.H., Katsuki, S. and Yoshida, H.: Factors which may regulate synthesis and release of acetylcholine in the nerve terminals of the rat brain. In Neurobiology of Chemical Transmission. Edited by Otsuka. M. and Hail. Z.W.. p. 77-89. John Wiley \& Sons, New York (1979)

28 Sciorelli, G., Poloni, M. and Rindi, G.: Evidence of cholinergic mediation of ingestive responses elicited by dibutyryl-adenosine-3, 5'-monophosphate in rat hypothalamus. Brain Res. 48 , 427-431 (1972)

29 Miyamoto, M.D. and Breckenridge, B. McL.: A cyclic adenosine monophosphate link in the catecholamine enhancement of transmitter release at the neuromuscular junction. J. Gen.
Physiol. 63, 609-624 (1974)

30 Alberts, P. and Stjärne, L.: Secretion of ${ }^{3} \mathrm{H}$ acetylcholine from guinea-pig ileum myenteric plexus is enhanced by $8-\mathrm{Br}$ adenosine $3^{\prime}, 5^{\prime}$ cyclic monophosphate but not changed by $8-\mathrm{Br}$ guanosine $3^{\prime}, 5^{\prime}$-cyclic monophosphate. Acta Physiol. Scand. 115, 269-272 (1982)

31 Reese, J.H. and Cooper, J.R.: Stimulation of acetylcholine release from guinea-pig ileal synaptosomes by cyclic nucleotides and forskolin. Biochem. Pharmacol. 33, 3007-3011 (1984)

32 Posternak, Th., Sutherland, E.W. and Henion, W.F.: Derivatives of cyclic 3',5'-adenosine monophosphate. Biochim. Biophys. Acta 65, $558-560(1962)$ 